\title{
The Relationship Between First-Trimester Aneuploidy Markers and Birth Weight
}

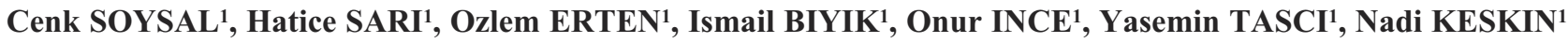 \\ Kutahya, Turkey
}

\section{ABSTRACT}

OBJECTIVE: We aimed to determine the relationship between the first-trimester aneuploidy screeningma and the predicted weight at birth: Small for gestational age and large for gestational age.

STUDY DESIGN: 594 low-risk pregnant women with a singleton pregnancy, who underwent firsttrimester aneuploidy screening by measuring nuchal translucency, maternal serum free beta-human chorionic gonadotropin, and pregnancy-associated plasma protein-A were included in the study. Those weighing above the $3^{\text {rd }}$ percentile and below the 10th percentile were defined as small for gestational age, and those over the 90th percentile were defined as large for gestational age.

RESULTS: A total of 594 pregnant women were enrolled. The mean maternal age of the studied group was $28.8 \pm 5.5$ years. Low maternal serum pregnancy-associated plasma protein-A levels and decreased nuchal translucency measurements were associated with the small for gestational age newborn $(p<0.001$ and $p=0.001$, respectively). There is a significant correlation with large for gestational age for newborns only with an increase in maternal serum pregnancy-associated plasma protein-A levels $(p=0.001)$. betahuman chorionic gonadotropin levels were not associated with the birth weight $(p=0.735)$.

CONCLUSION: Maternal serum pregnancy-associated plasma protein-A levels, one of the markers in firsttrimester aneuploidy screening, can be used in the prediction of small for gestational age and large for gestational age However, due to its low correlation, it is not a suitable screening test for clinical practice.

Keywords: Free beta-human chorionic gonadotropin, Large for gestational age, Nuchal translucency, Pregnancy-associated plasma protein-A, Small for gestational age

Gynecol Obstet Reprod Med 2021;27(3):207-212

\section{Introduction}

Birth weight is an important parameter for mortality and morbidity in the neonatal period. Although birth weight is affected by various factors, the main reasons are gestational age, genetic factors, BMI (Body Mass Index), maternal systemic

\footnotetext{
Kutahya University of Health Sciences, Department of Obstetrics and Gynecology Kutahya, Turkey Address of Correspondence: Cenk Soysal

Department of Obstetrics and Gynecology, Kutahya Health Sciences University

Faculty of Medicine, Evliya Celebi Campus on Tavsanll Road 10. km 43020

Kutahya, Turkey

drsoysalcenk@gmail.com
}

Submitted for Publication: 07.05.2021 Revised for Publication: 08.05.2021 Accepted for Publication: 27.08.2021 Online Published: 23.09.2021

ORCID IDs of the authors: $\quad$ CS: 0000-0003-1904-7282

HS: 0000-0001-7977-8461 OEn: 0000-0002-3178-8297

IB: 0000-0001-6111-9302 OI: 0000-0003-2263-8956

YT: 0000-0002-6612-7042 NK: 0000-0001-7097-7106

\begin{tabular}{c|c}
\hline Quick Response Code: & Access this article online \\
\cline { 2 - 2 } & Website: www.gorm.com.tr \\
& e- mail: info@gorm.com.tr \\
\cline { 2 - 2 } & DOI:10.21613/GORM.2021.1215 \\
\hline
\end{tabular}

How to cite this article: Soysal C. Sari H. Erten O. Biyik I. Ince O. Tasci Y. Keskin N. The Relationship between First-Trimester Aneuploidy Markers and Birth Weight. Gynecol Obstet Reprod Med. 2021;27(3):207-212 diseases, ethnic origin, maternal age, parity, and smoking habit (1-3). The rates of neonatal complications such as stillbirth, necrotizing enterocolitis, and respiratory distress syndrome increase in infants with small for gestational age (SGA) (defined as less than $10^{\text {th }}$ percentile birth weight) $(4,5)$. Similarly, large for gestational age (LGA) neonates (defined as over 90 percent of birth weight) have increased obstetric complications such as shoulder dystocia or other birth injuries and cesarean delivery, as well as a higher chance of complications such as obesity, cardiovascular disease, and metabolic imbalance in adulthood $(6,7)$.

In screening for first-trimester chromosomal abnormalities, measurement of fetal nuchal translucency (NT), evaluation of maternal serum pregnancy-associated plasma proteinA (PAPP-A), and free $\beta$-human chorionic gonadotropin ( $\beta$ hCG) levels are the part of antenatal care $(8,9)$. Although some studies on fetal birth weight have been conducted in the second trimester, few studies have examined the relationship between first-trimester aneuploidy markers and fetal weight (10-13). Early prediction of fetal growth abnormalities is crucial for postnatal care outcomes. However, screening methods have limited reliability due to varying sensitivity and high false-positive rates.

First-trimester aneuploidy markers compared with neonatal 
poor outcomes in the literature. Low maternal serum PAPP-A in the first trimester has an association with adverse pregnancy outcomes particularly if levels are very low ( $<1^{\text {st }}$ centile) (14). Increased NT has also been associated with poor obstetric outcomes, such as a decrease in PAPP-A (15). Nevertheless, the association between a low $\beta$-hCG level in the second trimester and adverse obstetric outcomes has been controversial (16).

In our study, we aimed to investigate whether the biochemical parameters used in first-trimester aneuploidy screening are related to birth weight and to determine the prediction accuracy of these parameters for SGA and LGA in newborns.

\section{Material and Method}

This study, designed retrospectively, was approved by the Kutahya Health Sciences University Ethics Committee (Decision no: 2020/14-02). Seven hundred and six patients who had first-trimester aneuploidy screening with NT, maternal serum $\beta$-hCG and PAPP-A markers between January 2018 and January 2020 in our clinic were included in the study. A total of 112 patients were excluded from the study: 48 due to delivery in another medical center, 21 due to fetal growth retardation, 17 due to fetal chromosomal anomalies, 16 due to preterm delivery, 9 due to multiple pregnancies, and 1 due to intrauterine ex fetus.

The data of the study were collected from hospital records. Fetal crown-rump length (CRL) was evaluated between 11 and 14 weeks by transabdominal or transvaginal ultrasonography. When a CRL between 45 and $84 \mathrm{~mm}$ was detected, NT measurements were evaluated by trained obstetricians. In addition, maternal serum PAPP-A and $\beta$-hCG levels at that time were measured using automated fluorometric immunological tests. The gestational age and maternal weight were reported as median (MoM) multiples adjusted for weight and smoking status. Birth weights were converted to percentiles by gestational age and gender at birth (17). The gestational age of the fetus at the time of delivery was calculated according to the CRL obtained during the aneuploidy screening performed in the first trimester. Those with a birth weight below the $10^{\text {th }}$ percentile were determined as SGA, neonates between the $10^{\text {th }}$ and $90^{\text {th }}$ percentile as the average for gestational age (AGA), and neonates above the $90^{\text {th }}$ percentile as LGA.

\section{Statistical Analysis}

Statistical analyses were performed using SPSS statistical software (version 25.0; SPSS Inc., Chicago, IL, USA) and R statistical computing software (version 3.6.1, https:/www.rproject.org/). The normality of the distribution of the variables was tested with the Kolmogorov Smirnov test. Continuous variables between the three groups were compared by busing the Kruskal Wallis-H Test. The post hoc pairwise comparisons were performed using the Wilcoxon test with Bonferroni correction. The mean, standard deviation, median and interquartile range of the variables were presented in the tables. A two-tailed $p$-value of $<0.05$ was considered significant. Correlations between birth weight and first trimester markers were estimated using Spearman's correlation coefficient. $p<0.05$ was considered to be statistically significant.

\section{Results}

A total of 594 patients were included in the study. The maternal age, gestational age at delivery, and birth weight for the study sample were $28.8 \pm 5.5$ years, $38.9 \pm 1.1$ weeks, and $3224 \pm 411 \mathrm{~g}$, respectively. The PAPP-A levels, NT measurements, and $\beta$-hCG levels were $0.91 \pm 0.51 \mathrm{MoM}, 0.84 \pm 0.30$ $\mathrm{mm}$, and $1.07 \pm 0.49 \mathrm{MoM}$, respectively in all groups.

Table I shows the comparison of PAPP-A, NT values, and

Table I: Demographics of the groups

\begin{tabular}{|c|c|c|c|c|}
\hline & SGA $(n=108)$ & AGA $(n=425)$ & LGA (n=61) & $p$ \\
\hline \multirow{2}{*}{ Maternal age (years) } & $28.5 \pm 5,5$ & $28,8 \pm 5.5$ & $29.2 \pm 5.4$ & \multirow{2}{*}{0.639} \\
\hline & $28.2[23.9 ; 32.7]$ & $28.3[24.5 ; 32,9]$ & $29.1[25.2 ; 32.8]$ & \\
\hline \multirow{2}{*}{ Duration of pregnancy (days) } & $272.8 \pm 7.4$ & $272.4 \pm 7.8$ & $268.6 \pm 6.6$ & \multirow{2}{*}{0.001} \\
\hline & $274.0[267.0 ; 278.0]$ & $273.0[266.0 ; 278.0]$ & $269.0[264.0 ; 273.0]$ & \\
\hline \multirow{2}{*}{ Birth weight (g) } & $2712.9 \pm 164.9$ & $3257.7 \pm 300.6$ & $3895.6 \pm 208.6$ & \multirow{2}{*}{$<0.001$} \\
\hline & $2701.5[2585.5 ; 2855.0]$ & $3240.0[3055.0 ; 3465.0]$ & $3900.0[3774.0 ; 4050.0]$ & \\
\hline \multirow{2}{*}{ PAPP-A (MoM) } & $0.7 \pm 0.3$ & $0.9 \pm 0.5$ & $1.1 \pm 0.6$ & \multirow{2}{*}{$<0.001$} \\
\hline & $0.7[0.5 ; 1.0]$ & $0.8[0.5 ; 1.2]$ & $1.0[0.8 ; 1.4]$ & \\
\hline \multirow{2}{*}{ NT (MoM) } & $0.8 \pm 0.3$ & $0.8 \pm 0.3$ & $1.0 \pm 0.4$ & \multirow{2}{*}{0.001} \\
\hline & $0.8[0.6 ; 1.0]$ & $0.8[0.7 ; 1.0]$ & $0.9[0.7 ; 1.3]$ & \\
\hline \multirow{2}{*}{$\beta$-hCG (MoM) } & $1.0 \pm 0.4$ & $1.1 \pm 0.5$ & $1.1 \pm 0.5$ & \multirow{2}{*}{0.735} \\
\hline & $1.0[0.7 ; 1.3]$ & $1.0[0.7 ; 1.3]$ & $1.0[0.8 ; 1.4]$ & \\
\hline
\end{tabular}

Values are presented as mean $\pm S D$, median [interquartile range], $n$ : Number, PAPP-A: Pregnancy-associated plasma protein-A, fß-hCG: Free beta human chorionic gonadotropin, NT: Nuchal translucency; CRL: Crown-rump length; MoM: Multiples of the expected median. $p$-values were calculated with the Kruskal Wallis test. The significant pairwise group comparison results were as represented below, For PAPP-A MoM: SGA vs AGA: $p=0.001$, SGA vs LGA: $p<0.001$, AGA vs LGA: $p=0.017$ (Post Hoc test: Tukey HSD), For NT MoM: SGA vs AGA: $p=0.81$, AGA vs LGA: $p<0.0001$, SGA vs LGA: $p=0.001$ (Post Hoc test: Tukey HSD), For hCG MoM: Pairwise comparison between groups has no significant value. 
$\beta$-hCG levels among the SGA, AGA, and LGA groups. $\beta$-hCG MoM levels were similar across the 3 groups $(p=0.735)$, while PAPP-A MoM levels differ significantly in all of the pairwise comparisons. NT values were significantly higher in the LGA group compared to AGA $(\mathrm{p}<0.001)$ and SGA $(p=0.001)$ groups.

Lastly, the correlation of MoM levels of PAPP-A, $\beta-\mathrm{hCG}$, and NT measurements with birth weight is presented in Table II. PAPP-A MoM levels and NT values showed a significant positive weak correlation with birth weight (Figure 1,2) ( $r=0.102, p=0.013$ and $r=0.116, p=0.005$, respectively). There was no significant correlation between aneuploidy parameters (PAPP-A, NT, and $\beta$-hCG) and birth weight according to the subgroup analysis of the birth weight categories, SGA, LGA, or AGA. The result of the correlation analysis for the subgroups was present in table III.

Table II: Correlation between birth weight and aneuploidy markers of the first trimester

\begin{tabular}{lcc}
\hline & $r$ & $p$ \\
\hline PAPP-A levels (MoM) & 0.102 & $\mathbf{0 . 0 1 3}$ \\
NT (MoM) & 0.116 & $\mathbf{0 . 0 0 5}$ \\
fß-hCG (MoM) & 0.04 & 0.32 \\
\hline
\end{tabular}

PAPP-A: Pregnancy-associated plasma protein-A, f $\beta$ - $h C G$ : Free beta human chorionic gonadotropin, NT: Nuchal translucency, CRL: Crownrump length, MoM: Multiples of the expected median

$r$ : Spearman's coefficient, $p<0.05$ was considered significant

Table III: The correlation between the birth weight and aneuploidy parameters for the different subgroups of birth weight

\begin{tabular}{lcccccc}
\hline & \multicolumn{2}{c}{ SGA } & \multicolumn{2}{c}{ AGA } & \multicolumn{2}{c}{ LGA } \\
\cline { 2 - 7 } & $r$ & $p$ & $r$ & $p$ & $r$ & $p$ \\
\cline { 2 - 7 } $\begin{array}{l}\text { PAPP-A } \\
\text { (MoM) }\end{array}$ & 0.100 & 0.302 & -0.60 & 0.215 & 0.03 & 0.804 \\
$\begin{array}{l}\text { NT } \\
\text { (MoM) }\end{array}$ & 0.001 & 0.993 & 0.056 & 0.251 & 0.045 & 0.732 \\
$\begin{array}{l}\text { fB-hCG } \\
\text { (MoM) }\end{array}$ & 0.005 & 0.961 & 0.082 & 0.092 & 0.032 & 0.807 \\
\hline
\end{tabular}

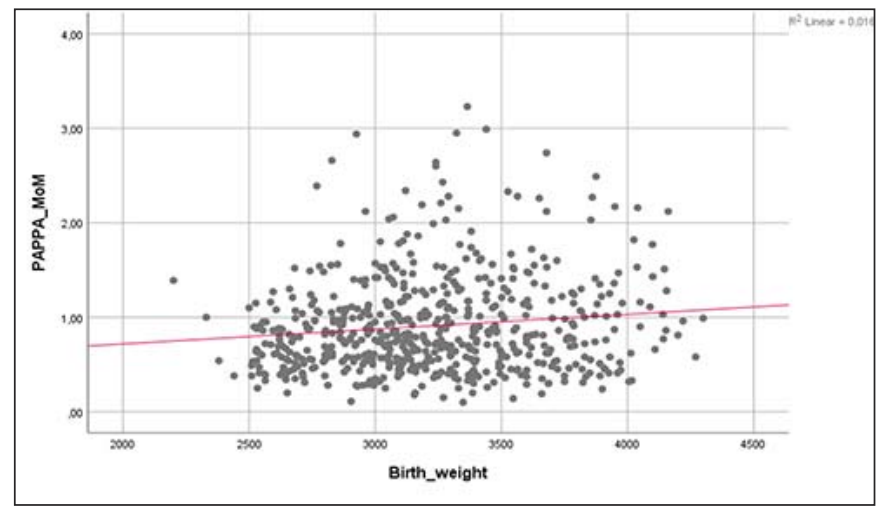

Figure 1: Positive weak correlation between birth weight and pregnancy-associated plasma protein- $A$ multiples of the expected levels

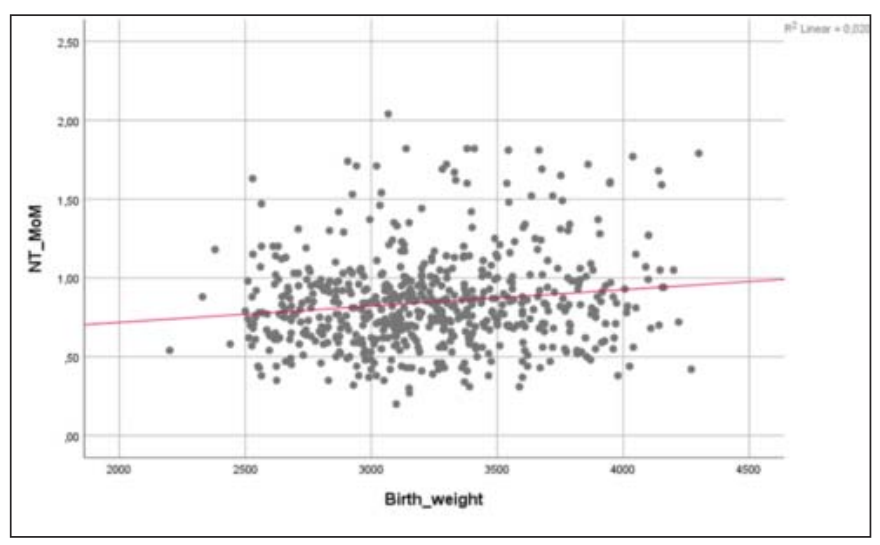

Figure 2: Positive weak correlation between birth weight and nuchal translucency multiples of the expected median levels

\section{Discussion}

This study aimed to investigate the relationship between birth weight and serum PAPP-A, $\beta$-hCG, and ultrasonographic NT measurements among the first-trimester aneuploidy markers. Although PAPP-A and NT measurements showed a positive but weak correlation with birth weight, $\beta$ hCG levels were unrelated to birth weight. It has been shown that pregnant women with high PAPP-A levels are associated with LGA, while low PAPP-A levels are associated with SGA. First-trimester fetuses with high NT measurements were associated with LGA, but low NT measurements were not associated with SGA. However, the maternal serum $\beta$-hCG level was not found to be associated with either SGA or LGA.

PAPP-A is used as part of routine screening for Down syndrome in the first trimester, and decreased serum levels are markers for chromosomal abnormalities (18). This factor is produced by placental syncytiotrophoblasts and interacts with insulin-like growth factor (IGF), playing a critical role in the trophoblast invasion stage as well as the growth of the placenta and the fetus (19). As the placental mass increases, PAPP-A levels increase in the maternal circulation and decrease rapidly in the postnatal period.

Many studies in the literature have shown the relationship between low maternal serum PAPP-A levels and SGA $(10,14$, 20-22). In this study, PAPP-A values were found to be useful in predicting SGA and LGA like other studies in the literature. A positive but weak relationship was found between low serum PAPP-A values and SGA in a study conducted in Turkey similar to our study in terms of population (23). Morris et al., in their meta-analysis in 2017, found that a low first-trimester serum PAPP-A level predicts SGA in newborns with an odds ratio of 2.83 (14). In the study of Boucoiran et al., a positive correlation was shown between first-trimester maternal serum PAPP-A values and SGA, but the same relationship was not found between high PAPP-A and neonates with LGA (10). The FASTER study, which includes 34,271 women, and Phil et al.'s study with 1734 women showed a correlation between low PAPP-A levels and pregnancy com- 
plications, including SGA newborns $(24,25)$. Similarly, although the increased maternal serum PAPP-A level was found to be associated with LGA in the study conducted by Spencer et al.,(26) the relationship between these two parameters is still controversial in the literature. While some studies establish a positive association between PAPP-A and LGA $(20,27$, $28)$, in some studies, this relationship has not been revealed. $(10,29)$. In the study conducted by DiPrisco et al., unlike maternal serum PAPP-A, it was shown that PAPP-A and PAPPA2 values measured from umbilical cord blood are inversely proportional to birth weight (29). In our study, there was no significant relationship between aneuploidy parameters (PAPP-A, NT, and $\beta$-hCG) and birth weight according to SGA, LGA, or AGA subgroup analysis. Therefore, PAPP-A, which is one of the first-trimester aneuploidy markers in predicting birth weight, would be more accurate to predict groups rather than subgroups.

Recent studies have begun to report a relationship between NT and birth weight in low-risk pregnant women. In their study on the population grouped as LGA and non-LGA, Weissman et al. claimed that increased first trimester NT measurements were associated with LGA (30). Hackmon et al.'s study in 2017 showed a correlation between birth weight and early fetal measurements such as biparietal diameter (BPD) and crown-rump length (CRL), NT measurements, and NT percentiles (11). There is a predominant opinion in the literature that a correlation exists between LGA and NT measurements $(2,10,13,27,30,31)$, but our study revealed no correlation between NT measurements and non-LGA AGA and SGA groups. Therefore, our data show that NT measurements within normal limits can be useful parameters for detecting future macrosomic or LGA fetuses. It has been emphasized in the literature that increased NT measurements (normal chromosomes and no structural anomalies) are associated with negative outcomes such as SGA, intrauterine growth restriction, and preterm labor in euploid fetuses $(15,32)$.

According to our study, while there was a significant difference in PAPP-A and NT measurements between SGA, AGA, and LGA groups, no significant difference was observed between $\beta$-hCG levels. Pakniat et al., in their study with 994 pregnant women, found that (in line with our study) low PAPP-A levels were associated with SGA, but $\beta$-hCG levels did not show this relationship (33). In the study by Hansen et al. from Denmark, 1155 pregnant women were divided into two groups as SGA and AGA. They showed that no difference occurred between the groups in terms of $\beta$-hCG and PAPP-A2 levels, but PAPP-A levels were lower in the SGA group (34). In their study with 658 pregnant women who did not have any risk factors, Dukhovny et al. found that although PAPP-A levels were associated with SGA, $\beta$-hCG levels were not associated with birth weight (21). In another study by Canini et al., no relationship was shown between birth weight and $\beta$-hCG (8). Contrary to these results, Karagiannis et al., in their study conducted on SGA and non-SGA in 2011, showed that $\beta$-hCG decreased, in addition to PAPP-A, in the SGA group (35). Therefore, although the opinion that there is no correlation between $\beta$-hCG and birth weight is dominant in the literature, this issue is still not definitive due to the relatively small sample sizes of these studies.

Our study has some limitations. The main limitations are that it is retrospective and has a small sample size. Some parameters such as placental parameters, uterine artery Doppler, maternal BMI, and gravida (which can be used in predicting SGA and LGA) were not included. The mentioned parameters could not be included in the study because they are not included in our patient records. Conducting our study in a single center is another limitation. The strength of our study is that while most of the studies in the literature focused on the prediction of SGA fetuses, our study included fetuses with LGA in addition to the SGA group.

In conclusion, among the parameters used in screening first trimester aneuploidies, maternal serum PAPP-A levels and ultrasonographic NT measurements can be used to predict birth weight in uncomplicated pregnancies. On the other hand, $\beta$-hCG measurement did not significantly contribute to the prediction of birth weight. PAPP-A and NT values are not yet recommended for clinical use due to the low correlation between SGA and LGA estimation. Prospective studies covering a wider population and including different parameters are needed in this area.

Acknowledgments: This study was conducted in accordance with the Declaration of Helsinki and was approved by Kutahya Health Sciences University Institutional Review Board and Ethics Committee with the project number: 2020 / 14-02. Consent of patients for using data was obtained. The authors would like to thank Dr. Anita L. Akkas (Middle East Technical University (ret), Ankara, Turkey) for contributing to the English editing.

Conflict of interest: The authors report no conflict of interest. Funding: None

Authors' Contributions: CS: Project development, manuscript writing, HS: Project development, data collection, NK: Data collection, manuscript editing, OE: Data collection, IB: Data collection, OI: Data collection, YT: Project development, manuscript editing

\section{References}

1. Montanari L, Alfei A, Albonico G, Moratti R, Arossa A, Beneventi $\mathrm{F}$, et al. The impact of first-trimester serum free beta-human chorionic gonadotropin and pregnancy-associated plasma protein A on the diagnosis of fetal growth restriction and small for gestational age infant. Fetal Diagn Ther. 2009;25(1):130-5. Doi: 10.1159/000207554.

2. Plasencia W, González Dávila E, Tetilla V, Padrón Pérez E, García Hernández JA, González González NL. First- 
trimester screening for large-for-gestational-age infants. Ultrasound Obstet Gynecol. 2012;39(4):389-95. Doi:10. 1002/uog.9060.

3. Poon LC, Karagiannis G, Staboulidou I, Shafiei A, Nicolaides KH. Reference range of birth weight with gestation and first-trimester prediction of small-for-gestation neonates. Prenat Diagn. 2011;31(1):58-65. Doi: 10.1002/ pd.2520.

4. de Bie HM, Oostrom KJ, Delemarre-van de Waal HA. Brain development, intelligence and cognitive outcome in children born small for gestational age. Horm Res Paediatr. 2010;73(1):6-14. Doi: 10.1159/000271911.

5. Pallotto EK, Kilbride HW. Perinatal outcome and later implications of intrauterine growth restriction. Clin Obstet Gynecol. 2006;49(2):257-69. Doi: 10.1097/00003081200606000-00008.

6. Bérard J, Dufour P, Vinatier D, Subtil D, Vanderstichèle $\mathrm{S}$, Monnier JC, et al. Fetal macrosomia: risk factors and outcome. A study of the outcome concerning 100 cases $>4500$ g. Eur J Obstet Gynecol Reprod Biol. 1998;77(1): 51-9. Doi: 10.1016/s0301-2115(97)00242-x.

7. Walsh JM, McAuliffe FM. Prediction and prevention of the macrosomic fetus. Eur J Obstet Gynecol Reprod Biol. 2012;162(2):125-30. Doi: 10.1016/j.ejogrb.2012.03.005.

8. Canini S, Prefumo F, Pastorino D, Crocetti L, Afflitto CG, Venturini PL, De Biasio P. Association between birth weight and first-trimester free beta-human chorionic gonadotropin and pregnancy-associated plasma protein A. Fertil Steril. 2008;89(1):174-8. Doi: 10.1016/j.fertnstert. 2007.02.024.

9. Zhong Y, Tuuli M, Odibo AO. First-trimester assessment of placenta function and the prediction of preeclampsia and intrauterine growth restriction. Prenat Diagn. 2010; 30(4):293-308. Doi: 10.1002/pd.2475.

10. Boucoiran I, Djemli A, Taillefer C, Rypens F, Delvin E, Audibert F. First-trimester prediction of birth weight. Am J Perinatol. 2013;30(8):665-72. Doi: 10.1055/s-0032-133 1023.

11. Hackmon R, Librach C, Burwick R, Rodrigues N, Farine D, Berger H. Do early fetal measurements and nuchal translucency correlate with term birth weight? J Obstet Gynaecol Can. 2017;39(9):750-6. Doi: 10.1016/j.jogc. 2017.04.034.

12. Işikalan MM, Yeniçeri H, Acar A. Relation of nuchal fold thickness with maternal characteristics and birth weight. Cukurova Med J. 2020;45(4):1444-8. Doi:10.17826/cumj. 734846 .

13. Kalem Z, Ellibeş Kaya A, Bakırarar B, Namlı Kalem M. Fetal nuchal translucency: is there an association with birthweight and neonatal wellbeing? Turk J Obstet Gynecol. 2019;16(1):35-40. Doi: 10.4274/tjod.galenos. 2019.21384 .

14. Morris RK, Bilagi A, Devani P, Kilby MD. Association of serum PAPP-A levels in first trimester with small for gestational age and adverse pregnancy outcomes: systematic review and meta-analysis. Prenat Diagn. 2017;37(3):25365. Doi: 10.1002/pd.5001.

15. Shakoor S, Dileep D, Tirmizi S, Rashid S, Amin Y, Munim S. Increased nuchal translucency and adverse pregnancy outcomes. J Matern Fetal Neonatal Med. 2017;30(14):1760-3. Doi: 10.1080/14767058.2016. 1224 836.

16. Sirikunalai P, Wanapirak C, Sirichotiyakul S, Tongprasert F, Srisupundit K, Luewan S, et al. Associations between maternal serum free beta human chorionic gonadotropin $(\beta$-hCG) levels and adverse pregnancy outcomes. J Obstet Gynaecol. 2016;36(2):178-82. Doi: 10.3109/01443615. 2015.1036400 .

17. Gökçay G, Furman A, Neyzi O. Updated growth curves for Turkish children aged 15 days to 60 months. Child Care Health Dev. 2008;34(4):454-63. Doi: 10.1111/j. 1365-2214.2008.00813.x.

18. Kalousová M, Muravská A, Zima T. Pregnancy-associated plasma protein A (PAPP-A) and preeclampsia. Adv Clin Chem. 2014;63:169-209. Doi: 10.1016/b978-0-12800094-6.00005-4.

19. Kirkegaard I, Uldbjerg N, Oxvig C. Biology of pregnancy-associated plasma protein-A in relation to prenatal diagnostics: an overview. Acta Obstet Gynecol Scand. 2010;89(9):1118-25. Doi: 10.3109/00016349.2010.505 639.

20. Baer RJ, Lyell DJ, Norton ME, Currier RJ, JelliffePawlowski LL. First trimester pregnancy-associated plasma protein-A and birth weight. Eur J Obstet Gynecol Reprod Biol. 2016;198:1-6. Doi: 10.1016/j.ejogrb.2015. 12.019 .

21. Dukhovny S, Zera C, Little SE, McElrath T, WilkinsHaug L. Eliminating first trimester markers: will replacing PAPP-A and $\beta$ hCG miss women at risk for small for gestational age? J Matern Fetal Neonatal Med. 2014; 27(17):1761-4. Doi: 10.3109/14767058.2013.879 703.

22. Krantz D, Goetzl L, Simpson JL, Thom E, Zachary J, Hallahan TW, et al. Association of extreme first-trimester free human chorionic gonadotropin-beta, pregnancy-associated plasma protein A, and nuchal translucency with intrauterine growth restriction and other adverse pregnancy outcomes. Am J Obstet Gynecol. 2004;191(4):1452-8. Doi: 10.1016/j.ajog.2004.05.068.

23. Kokanalı D, Coskun B, Kokanalı MK, Taşçı Y. Association between first-trimester aneuploidy markers and birth weight. J Clin Anal Med 2017;8(suppl 2):125-8. Doi: 10.4328/JCAM.4894.

24. Dugoff L, Hobbins JC, Malone FD, Porter TF, Luthy D, Comstock $\mathrm{CH}$, et al. First-trimester maternal serum PAPP-A and free-beta subunit human chorionic gonadotropin concentrations and nuchal translucency are associated with obstetric complications: a population-based 
screening study (the FASTER Trial). Am J Obstet Gynecol. 2004;191(4):1446-51. Doi: 10.1016/j.ajog.2004. 06.052 .

25. Pihl K, Sørensen TL, Nørgaard-Pedersen B, Larsen SO, Nguyen TH, Krebs L, et al. First-trimester combined screening for Down syndrome: prediction of low birth weight, small for gestational age and pre-term delivery in a cohort of non-selected women. Prenat Diagn. 2008;28(3):247-53. Doi: 10.1002/pd.1946.

26. Spencer K, Cowans NJ, Avgidou K, Molina F, Nicolaides KH. First-trimester biochemical markers of aneuploidy and the prediction of small-for-gestational age fetuses. Ultrasound Obstet Gynecol. 2008;31(1):15-9. Doi:10. 1002/uog.5165.

27. González González NL, Plasencia W, González Dávila E, Padrón E, di Renzo GC, Bartha JL. First and second trimester screening for large for gestational age infants. J Matern Fetal Neonatal Med. 2013;26(16):1635-40. Doi: 10.3109/14767058.2013.794779.

28. Plasencia W, Akolekar R, Dagklis T, Veduta A, Nicolaides KH. Placental volume at 11-13 weeks' gestation in the prediction of birth weight percentile. Fetal Diagn Ther. 2011;30(1):23-8. Doi: 10.1159/000324318.

29. DiPrisco B, Kumar A, Kalra B, Savjani GV, Michael Z, Farr O, et al. Placental proteases PAPP-A and PAPP-A2, the binding proteins they cleave (IGFBP-4 and -5), and IGF-I and IGF-II: Levels in umbilical cord blood and associations with birth weight and length. Metabolism. 2019;100:153959. Doi: 10.1016/j.metabol.2019.153959.
30. Weissmann-Brenner A, Weisz B, Lerner-Geva L, Gindes $\mathrm{L}$, Achiron R. Increased nuchal translucency is associated with large for gestational age neonates in singleton pregnancies. J Perinat Med. 2011;39(3):305-9. Doi: 10.1515/ jpm.2011.009.

31. Timmerman E, Pajkrt E, Snijders RJ, Bilardo CM. High macrosomia rate in healthy fetuses after enlarged nuchal translucency. Prenat Diagn. 2014;34(2):103-8. Doi: 10.1002/pd.4262.

32. Tiyatha S, Sirilert S, Sekararithi R, Tongsong T. Association between unexplained thickened nuchal translucency and adverse pregnancy outcomes. Arch Gynecol Obstet. 2018;298(1):97-101. Doi: 10.1007/ s00404-018-4790-9.

33. Pakniat H, Bahman A, Ansari I. The relationship of pregnancy-associated plasma protein a and human chorionic gonadotropin with adverse pregnancy outcomes: a prospective study. J Obstet Gynaecol India. 2019;69(5): 412-419. Doi: 10.1007/s13224-019-01217-3.

34. Hansen YB, Myrhøj V, Jørgensen FS, Oxvig C, Sørensen S. First trimester PAPP-A2, PAPP-A and hCG $\beta$ in smallfor-gestational-age pregnancies. Clin Chem Lab Med. 2016;54(1):117-23. Doi: 10.1515/cclm-2015-0230.

35. Karagiannis G, Akolekar R, Sarquis R, Wright D, Nicolaides KH. Prediction of small-for-gestation neonates from biophysical and biochemical markers at 11-13 weeks. Fetal Diagn Ther. 2011;29(2):148-54. Doi:10. 1159/000321694. 